\title{
PENGARUH KOMPETENSI, BUDAYA ORGANISASI DAN MOTIVASI TERHADAP KINERJA DOSEN PERGURUAN TINGGI SWASTA DI KOTA MAKASSAR
}

\author{
Oleh : \\ Rina \\ Dosen STIM-LPI Makassar \\ E-mail : rinajanny78@gmail.com \\ Aditya Halim Perdana Kusuma (Contributors) \\ Dosen STIM-Lasharan Jaya Makassar \\ E-mail : adityatrojhan@gmail.com
}

\begin{abstract}
The phenomenon faced by the lecturers of Kopertis Region IX which is seconded because of the policy of the PTS managers who give less trust or responsibility and the opportunity to the lecturer to provide workload according to the guideline of BKD which has been determined, the policy of lecturer planning planning by the institution pay less attention to the mapping aspect and the low direct supervision of the private university leadership to lecturers. This is of course a deep-rooted problem rather than an unprofessional organizational culture of the faculty (Lecturer) within the scope of private universities so that private university teachers are not so motivated to further develop their own potentials that impact on the lecturer's performance. On the other hand lecturer competence is dominantly felt has been fulfilled through education programs that have been taken both formal and training. This study used a sample of 255 university lecturers with sampling using stratified random sampling method. The variables in this research are competence (X1), Organizational Culture (X2) Motivation (X3) and Lecturer Performance (Y). The result of this research stated that the competence, organizational culture, motivation have a significant effect on lecturer performance.
\end{abstract}

Keywords : Competence, Organizational Culture, Motivation, Performance 


\section{PENDAHULUAN}

Sistem pendidikan nasional harus mampu menjadi pemerataan kesempatan pendidikan, peningkatan mutu secara determinan dan efisiensi manajemen pendidikan untuk menghadapi tantangan sesuai dengan tuntutan perubahan kehidupan lokal, nasional dan global sehingga diperlukan pembaharuan secara terencana, terarah dan berkesinambungan (UU. No. 20 tahun 2003).

Pendidikan merupakan faktor yang penting bagi kehidupan manusia. Karena manusia berbudaya dan mampu terus mengembangkan budaya tersebut demi mencapai kehidupan yang lebih baik. Serta berperan tidak hanya dalam pembentukan individu melainkan juga dalam pembentukan budaya masyarakat menuju kualitas hidup yang lebih baik. Pentingnya fungsi dan peran dosen dalam perguruan tinggi, setiap dosen perlu meningkatkan kinerja dalam melakukan pekerjaan. Demikian halnya dengan perguruan tinggi sebagai lembaga yang menyelenggarakan pendidikan tinggi sangat ditunjang oleh adanya kinerja yang diberikan oleh Dosen dalam melakukan proses pembelajaran kepada peserta didik. Menurut Depdiknas yang dilangsir Trisnaningsih (2011) yang menyatakan bahwa kinerja dosen adalah kemampuan untuk melakukan pekerjaan atau tugas yang dimiliki dalam menyelesaikan pekerjaan.

Berdasarkan data yang ada di Kopertis Wilayah IX jumlah dosen perguruan tinggi swasta yang ada di Kota Makassar sebanyak 704 orang Dosen DPK yang terdiri dari PTS berbentuk Universitas / Institut 448 orang, PTS berbentuk sekolah tinggi 231 orang dan PTS yang berbentuk akademi / Politeknik 25 orang. Faktor yang mempengaruhi kinerja dosen dalam melakukan pekerjaan adalah kepuasan kerja sebab kepuasan kerja berkaitan erat dengan kinerja pegawai. Masalah kepuasan kerja dan kinerja dosen merupakan bagian yang terpenting yang harus diperhatikan oleh setiap pengelola Perguruan tinggi. Dimana dengan kepuasan kerja yang tinggi akan berdampak terhadap kinerja dosen. Upaya dalam meningkatkan kepuasan dan kinerja dosen khususnya dalam lingkup Perguruan Tinggi maka perlu ditunjang oleh adanya kompetensi yang dimiliki oleh setiap dosen dalam melakukan proses pembelajaran dari 
setiap mata kuliah yang diajarkan, karena berpengaruh terhadap kepuasan kerja sehingga berdampak terhadap kinerja yang dicapai. Kompetensi merupakan bagian yang terpenting dalam pencapaian kinerja. kompetensi adalah suatu hal yang menggambarkan kualifikasi atau kemampuan seseorang baik yang bersifat kualitatif maupun yang kuantitatif. Sehingga Kusnandar (2007:55). Faktor lainnya yang mempengaruhi kepuasan kerja dan kinerja dosen adalah budaya organisasi. Mulyadi (2015:95) yang mengatakan bahwa budaya organisasi adalah nilai dan semangat yang mendasar dalam cara mengelola serta mengorganisasikan, sehingga budaya organisasi merupakan bagian yang terpenting dalam pengembangan dalam suatu organisasi. Selain daripada itu motivasi juga merupakan factor yang mempengaruhi kinerja dosen perguruan tinggi sebab Motivasi adalah kekuatan yang ada dalam diri seseorang yang mendorong perilaku untuk melakukan tindakan. Besarnya intensitas kekuatan dari dalam diri seseorang untuk melakukan suatu tugas atau mencapai sasaran memperlihatkan sejauh mana tingkat motivasi (Widodo, 2015:187). Untuk lebih jelasnya akan disajikan laporan kinerja dosen periode 2013-2014 yang dapat dilihat pada tabel 1 yaitu sebagai berikut :

Tabel 1 Penilaian Kinerja Dosen berdasarkan Tridarma dan kegiatan Penunjang pada Kopertis Wilayah IX Kota Makassar

\begin{tabular}{clcccc}
\hline No & Jenis PTS & $\begin{array}{c}\text { Pendidikan } \\
\text { dan } \\
\text { Pengajaran }\end{array}$ & Penelitian & $\begin{array}{c}\text { Pengabdian } \\
\text { Masyarakat }\end{array}$ & $\begin{array}{c}\text { Tugas } \\
\text { Penunjang }\end{array}$ \\
\cline { 3 - 6 } & SKS & SKS & SKS & SKS \\
\hline $\mathbf{1}$ & Universitas/Institut & 6 & 2 & 1 & 2 \\
\hline $\mathbf{2}$ & Sekolah Tinggi & 5 & 2 & 1 & 2 \\
\hline $\mathbf{3}$ & Akademik/Poltek & 5 & 1 & 1 & 2 \\
\hline
\end{tabular}

Sumber : Kopertis Wilayah IX kota Makassar, 2017

Fenomena yang dihadapi oleh dosen Kopertis Wilayah IX yang diperbantukan dikarenakan kebijakan dari pengelola PTS yang kurang 
memberikan kepercayaan atau tanggung jawab dan kesempatan kepada dosen yang masih muda untuk memberikan beban kerja sesuai pedoman BKD yang telah ditentukan, kebijakan penyusunan perencanaan dosen oleh lembaga kurang memperhatikan aspek pemetaan kebutuhan dan serta rendahnya pengawasan langsung pimpinan PTS ke dosen.

Fenonema lain masih banyak dosen muda yang belum melibatkan diri dalam bidang penelitian khususnya yang berkaitan dengan penelitian pribadi, penelitian persaingan secara kolektif dan berbagai penelitian karya tulis ilmiah/jurnal. Ini dikarenakan minimnya pengetahuan tentang metodologi penelitian sehingga para dosen tersebut sangat kesulitan melakukan penelitian. Ini bisa terlihat dari jumlah 740 orang dosen yang diperbantukan di 110 PTS di Makassar, hanya beberapa orang yang aktif dan memiliki kemampuan layak untuk melakukan penelitian. Sementara yang lainnya tak banyak melakukan penelitian dan hanya menunggu pada proses menyampaikan perkuliahan pada mahasiswa

Berkaitan dengan UU. No. 14 tahun 2005 pasal 72 ayat (1) yang menyatakan bahwa beban kerja dosen mencakup kegiatan pokok yaitu merencanakan pembelajaran, melakukan proses pembelajaran, melakukan evaluasi pembelajaran, membimbing dan melatih, melakukan tugas tambahan serta melakukan pengabdian masyarakat.

Selanjutnya ayat (2) bahwa beban kerja dosen sekurang-kurangnya sepadan dengan 12 satuan kredit semester (SKS) dan sebanyak 16 Satuan Kredit Semester. Sedangkan dari laporan kinerja dosen Kopertis Wilayah IX yang diperbantukan pada PTS di kota Makassar terlihat bahwa kinerja dosen pada PTS Universitas, Akademi dan Politeknik tidak ada yang mencapai 12 SKS s/d 16 SKS.

\section{TINJAUAN PUSTAKA}

Dosen adalah orang yang memegang peran penting dalam merancang strategi perkuliahan yang akan dilakukan. Keberhasilan proses perkuliahan sangat tergantung pada penampilan dosen dalam mengajar dan kegiatan 
mengajar dapat dilakukan dengan baik dan benar oleh seseorang yang telah melewati pendidikan tertentu yang memang dirancang untuk mempersiapkan sebagai seorang dosen. Pernyataan tersebut mengantarkan kepada pengertian bahwa mengajar adalah suatu profesi, dan pekerjaan dosen adalah pekerjaan profesional. Setiap pekerjaan profesional dipersyaratkan memiliki kemampuan atau kompetensi tertentu agar yang bersangkutan dapat melaksanakan tugastugas profesionalnnya. Zamroni (2011: 60). Suparlan (2006: 85) menjelaskan bahwa standar kompetensi dosen adalah ukuran yang ditetapkan atau dipersyaratkan dalam bentuk penguasaan pengetahuan dan perilaku perbuatan bagi seorang dosen agar berkelayakan untuk menduduki jabatan fungsional sesuai dengan bidang tugas, kualifikasi dan jenjang pendidikan.

Kompetensi merupakan perpaduan dari pengetahuan, ketrampilan, nilai dan sikap yang direfleksikan dalam kebiasaan berpikir dan bertindak. Pada sistem pengajaran, kompetensi digunakan untuk mendeskripsikan kemampuan profesional yaitu kemampuan untuk menunjukkan pengetahuan dan konseptualisasi pada tingkat yang lebih tinggi. Kompetensi ini dapat diperoleh melalui pendidikan, pelatihan dan pengalaman lain sesuai tingkat kompetensinya. Mulyasa (2012:37-38). Kemampuan mengajar dosen sebenarnya merupakan pencerminan dosen atas kompetensinya. Kompetensi ini terdiri dari berbagai komponen penting. Nana Sudjana (2002:17) mengutip pendapat Cooper bahwa ada empat kompetensi yang harus dimiliki dosen, yaitu:

a. Mempunyai pengetahuan tentang belajar tingkah laku manusia.

b. Mempunyai pengetahuan dan menguasai bidang studi yang dibinanya.

c. Mempunyai kemampuan tentang teknik mengajar

d. Mempunyai sikap yang tepat tentang dirinya, sekolah, teman sejawat dan bidang studi yang dibinanya.

Sementara itu menurut pendapat Glasser yang dikutip Nana Sudjana (2002: 18) yang menyebutkan ada empat yang harus dikuasai oleh dosen, meliputi: 1) menguasai bahan pelajaran, 2) kemampuan mendiagnosa tingkah laku mahasiswa, 3) kemampuan melaksanakan proses perkuliahan, 4) kemampuan mengukur hasil belajar mahasiswa. Kompetensi yang wajib dimiliki 
oleh seorang dosen adalah kompetensi pedagogik yang terdiri dari penguasaan karakteristik peserta didik, penguasan teori dan prinsip pembelajaran, pengembangan kurikulum dan rancangan pembelakaran, penyelenggaraan pembelajaraan dan pemanfaatan teknologi informasi serta memfasilitasi pengembangan potensi peserta didik. Selain daripada itu kompetensi profesional dan kompetensi kepribadian serta kompetensi sosial merupakan kompetensi wajib dimiliki oleh seorang dosen.

Budaya organisasi merupakan kebiasaan, tradisi, dan tata cara umum dalam melakukan sesuatu dan sebagian besar berasal dari pendiri organisasi. Secara tradisional pendiri organisasi memiliki pengaruh yang besar terhadap budaya awal organisasi. Mereka memiliki visi tentang akan menjadi apa organisasi itu nantinya. Mereka juga tidak memiliki kendala karena kebiasaan atau ideologi sebelumnya. Ukuran kecil organisasi yang merupakan ciri ketika organisasi baru pertama kali berdiri, lebih memudahkan pendiri untuk memaksakan visi mereka kepada sesluruh anggota organisasi. Sunyoto (2012:226). Budaya organisasi dari Robbins (2012) menyatakan bahwa karakteristik daripada budaya organisasi adalah 1). Inisiatif individual, 2) toleransi terhadap tindakan beresiko 3) pengarahan, 4). Integrasi 5) Dukungan Manajemen 6). Kontrol 7). Identitas, 8). Sistem imbalan 9). Toleransi terhadap konflik dan 10) pola komunikasi.

Kompetensi dosen merupakan karakteristik dasar seorang dosen yang menggunakan bagian kepribadianya yang paling dalam dan dapat mempengaruhi perilakunya ketika ia menghadapi pekerjaan. Kompetensi juga merupakan karakteristik dasar seorang pekerja yang menggunakan bagian kepribadiannya yang paling dalam dan dapat mempengaruhi perilakunya ketika ia menghadapi pekerjaan yang akhirnya mempengaruhi kemampuan untuk meningkatkan prestasi kerjanya. Sedangkan kepuasan dosen adalah kumpulan perasaan enak dan tidak enak dimana dosen menemukan suasana kerja mereka. Apabila seorang dosen memiliki tingkat kompetensi yang tinggi maka akan memiliki tingkat kepuasan yang tinggi pula, karena dengan memiliki kompetensi secara beriringan kepuasan akan pekerjaannya akan timbul dalam diri karyawan. 
Dengan demikian dapat dipahami bahwa dosen yang mempunyai kompetensi tinggi dan tercukupi kebutuhan hidupnya akan menunjukkan kepuasan kerja yang lebih baik

UU Nomor 14 Tahun 2005 tentang Guru dan Dosen, dan Peraturan Pemerintah Republik Indonesia Nomor 37 Tahun 2009 tentang Dosen, disebutkan bahwa dosen adalah pendidik profesional dan ilmuwan dengan tugas utama mentransformasikan, mengembangkan dan dan menyebarluaskan ilmu pengetahuan, teknologi, dan seni melalui pendidikan, penelitian dan pengabdian kepada masyarakat (Tridarma Perguruan Tinggi). Kinerja Depdiknas (2004), menyatakan kinerja dosen adalah kemampuan untuk melaksanakan pekerjaan atau tugas yang dimiliki dosen dalam menyelesaikan suatu pekerjaannya. Kinerja atau performansi dapat diartikan sebagai presentasi kerja, pelaksanaan kerja, pencapaian kerja, hasil kerja atau unjuk kerja (LAN, 2004). Sejalan dengan itu Smith (2002: 393) menyatakan, kinerja adalah output drive from processes, human or otherwise. Jadi, kinerja merupakan hasil atau keluaran dari suatu proses. Untuk lebih memahami tentang kinerja dosen. Kriteria kinerja pendidikan menurut Blazey, et al. (2003: 31) bertujuan untuk :

a) Meningkatkan kinerja, kapabilitas, dan output pendidikan,

b) Mempermudah komunikasi dan tukar menukar informasi tentang praktik pendidikan yang terbaik dengan berbagai tipe institusi pendidikan, dan

c) Sebagai alat untuk memahami dan meningkatkan kinerja institusi pendidikan serta pedoman dalam perencanaan stratejik.

Bagi suatu organisasi, kinerja merupakan hasil dari kegiatan kerja sama diantara para anggota atau komponen organisasi dalam rangka mewujudkan tujuan organisasi. Proses yang terjadi dalam organisasi yaitu berfungsinya manajemen melalui fungsi fundamentalnya, yaitu planning, organizing, actuating and controlling disingkat dengan (POAC) secara terpadu. 


\section{METODE PENELITIAN}

Penelitian dilakukan pada beberapa perguruan tinggi swasta dalam lingkup Kopertis Wilayah IX di Kota Makassar, sampel penelitian ini 255 responden yakni Universitas 162 responden, Sekolah Tinggi 84 respondend, Akademi 9 Responden. Metode pengambilan sampel menggunakan stratified random sampling. Teknik pengumpulan data menggunakan kuesioner dan dokumentasi. Teknik analisis data menggunakan Struqtural Equation Model (SEM). Defensi operasional variable seperti dibawah ini :

\section{Tabel 2. Defenisi Operasional Variabel}

\section{No Variabel}

Konsep

Indikator

1 Kompetensi (X1)

2 Budaya Organisasi (X2)

3 Motivasi $\operatorname{Kerja}(\mathrm{X} 3)$

4 Kinerja $\operatorname{Dosen}(\mathrm{Y})$
Seperangkat penguasaan kemampuan yang harus ada dalam diri dosen agar dapat mewujudkan kinerja secara tepat dan efisien.

Sistem makna bersama yang dianut oleh anggota yang membedakan organisasi tersebut dengan orang lain
- Pendagogik

- Profesional

- Kepribadian

- Sosial

- Inovasi

- Perhatian terhadap detail

- Orientasi hasil

- Orientasi orang

- orientasi tim

- Keagresifan

- kebutuhan fisiologis

- Kebutuhan rasa aman

- Kebutuhan hubungan sosial

- Kebutuhan pengakuan

- Kebutuhan aktualissi diri

- Pendidik dan pengajar

- Penelitian dan pengembangan karya ilmiah

- Pengabdian kepada masyaraka

- Kegiatan penunjang karier

\section{HASIL PENELITIAN}

Responden dalam penelitian ini adalah Laki-laki 162 orang (63,5\%), dan perempuan 93 orang $(36,5 \%)$. Berdasarkan umur responden $<25$ tahun $=0$ orang, 26-39 tahun $=7$ orang, 40-49 tahun $=154$ orang, $>50$ tahun $=94$ orang. Berdasarkan pendidikan terakhir yakni $\mathrm{S} 1=3$ orang, $\mathrm{S} 2=189$ orang, S3 = 63 
orang. Berdasarkan masa kerja, 5-10 tahun $=7$ orang, 11-20 tahun $=87$ orang, 21-25 tahun $=96$ orang, diatas 26 tahun $=65$ orang. Berdasarkan status pernikahan yakni menikah $=220$ orang, Belum menikah $=35$ orang. Uji validitas penelitian adalah :

\section{Tabel 3. Uji Validitas}

$\begin{array}{ccccc}\text { Variabel Penelitian } & \text { Indikator Penelitian } & \mathbf{r}_{\text {hitung }} & \mathbf{r}_{\text {tabel }} & \text { Keputusan } \\ \text { 1. Kompetensi (X1) } & \text { X1.1 } & 0,747 & 0,30 & \text { Valid } \\ & \text { X1.2 } & 0,516 & 0,30 & \text { Valid } \\ \text { 2. Budaya organisasi (X2) } & \text { X1.3 } & 0,657 & 0,30 & \text { Valid } \\ & \text { X1.4 } & 0,585 & 0,30 & \text { Valid } \\ & \text { X2.1 } & 0,806 & 0,30 & \text { Valid } \\ & \text { X2.2 } & 0,597 & 0,30 & \text { Valid } \\ & \text { X2.3 } & 0,553 & 0,30 & \text { Valid } \\ & \text { X2.4 } & 0,527 & 0,30 & \text { Valid } \\ \text { 3. Motivasi kerja (X3) } & \text { X2.5 } & 0,580 & 0,30 & \text { Valid } \\ & \text { X2.6 } & 0,548 & 0,30 & \text { Valid } \\ & \text { X3.1 } & 0,740 & 0,30 & \text { Valid } \\ & \text { X3.2 } & 0,484 & 0,30 & \text { Valid } \\ & \text { X3.3 } & 0,443 & 0,30 & \text { Valid } \\ \text { 6. Kinerja dosen (Y2) } & \text { X3.4 } & 0,496 & 0,30 & \text { Valid } \\ & \text { X3.5 } & 0,529 & 0,30 & \text { Valid } \\ & \text { Y2.1 } & 0,637 & 0,30 & \text { Valid } \\ & \text { Y2.2 } & 0,563 & 0,30 & \text { Valid } \\ & \text { Y2.3 } & 0,564 & 0,30 & \text { Valid } \\ & \text { Y2.4 } & 0,464 & 0,30 & \text { Valid }\end{array}$

Hasil uji reliabilitas dari masing-masing variabel penelitian, dimana untuk variabel kompetensi dengan 4 item pertanyaan dan memiliki cronbach's alpha 0,808 > 0,60 berarti keempat indikator penelitian sudah andal/reliabel. Kemudian budaya organisasi diukur dengan 6 item pertanyaan, karena cronbach's alpha 0,827 > 0,60 maka kesimpulan yang dapat diambil dalam penelitian ini bahwa keenam indikator pertanyaan andal/reliabel. Kemudian untuk motivasi kerja memiliki 5 item pertanyaan dengan nilai cronbach's alpha 0,762>0,60 berarti kesimpulan yang dapat diambil bahwa kelima indikator penelitian andal/reliabel. Kemudian untuk komitmen organisasi dengan 3 item pertanyaan dimana memiliki cronbach's alpha 0,761 > 0,60 berarti dapat dikatakan bahwa ketiga item pertanyaan sudah andal/reliabel. Sedangkan kepuasan kerja dengan 5 item 
Hipotesis yang menyatakan bahwa budaya organisasi berpengaruh signifikan terhadap kinerja dosen Kopertis Wilayah IX yang diperbantukan pada PTS di Makassar. Hasil uji hipotesis menunjukkan bahwa critical ratio (cr) yaitu sebesar 2,746 > 1,96. Selain itu dilihat dari $\rho$ value $(\mathrm{P})$ yaitu: $0,006<0,05$. Berarti budaya organisasi berpengaruh positif dan signifikan terhadap kinerja dosen Kopertis Wilayah IX yang diperbantukan pada PTS di Makassar, sehingga dalam penelitian ini hipotesis dapat diterima.

c. Pengaruh motivasi kerja terhadap kinerja dosen Kopertis Wilayah IX yang diperbantukan pada PTS di Makassar

Pengujian hipotesis menyatakan bahwa motivasi kerja berpengaruh signifikan terhadap kinerja dosen Kopertis Wilayah IX yang diperbantukan pada PTS di Makassar, diuji dengan melihat dari nilai critical ratio 2,518 $>1,96$, selain itu memiliki nilai $\rho$ value $(\mathrm{P})=0,012<0,05$. Berarti ada pengaruh signifikan motivasi kerja dengan kinerja dosen Kopertis Wilayah IX yang diperbantukan pada PTS di Makassar, sehingga dari hasil uji hipotesis dapat diterima.

\section{PEMBAHASAN}

Dosen Kopertis Wilayah IX yang diperbantukan pada PTS di Makassar maka dapat dikatakan bahwa kompetensi dosen sudah baik. Hal ini dilihat dari masa kerja dosen rata-rata relah memiliki jenjang pendidikan Magister (S2) dan Doktor (S3). Kemudian dilihat dari masa kerja dosen sebagian besar telah memiliki masa kerja yang lebih dari 25 tahun sehingga dapat dikatakan bahwa kompetensi dosen pada PTS di Makassar sudah memiliki pengalaman dan selain itu memiliki jenjang pendidikan Magister dan Doktor. Sehingga dengan kompetensi dosen akan mempengaruhi kepuasan dosen, sehingga dari hasil penelitian ini dapat dikatakan ada pengaruh positif terhadap kepusan dosen. Berarti secara empirik dari pengamatan ini dapat dikatakan bahwa salah satu faktor yang dapat meningkatkan kepuasan dosen Kopertis Wilayah IX yang diperbantukan pada PTS di Makassar adalah kompetensi yang dimiliki selama ini sebab dengan adanya peningkatan kompetensi dosen maka akan dapat memberikan dampak terhadap kepuasan dosen.Kemudian dilihat dari hasil uji 
hipotesis dapat dikatakan ada pengaruh signifikan antara kompetensi dengan kepuasan dosen Kopertis Wilayah IX yang diperbantukan pada PTS di Makassar. Hal ini dilihat dari hasil persepsi dosen menyatakan pengaruh secara signifikan antara kompetensi dengan kepuasan. Sehingga dari hasil pengamatan dalam penelitian ini dapat dikatakan bahwa kepuasan dosen dapat ditingkatkan dengan adanya peningkatan kompetensi kerja.

Masalah budaya organisasi dalam lingkup Kopertis Wilayah IX merupakan bagian yang terpenting dalam peningkatan kepuasan dan kinerja dosen. Sehingga menurut Riani (2011) bahwa budaya organisasi adalah nilai-nilai, keyakinan dan prinsip-prinsip dasar yang merupakan landasan bagi sistem dan praktek-praktek manajemen serta perilaku yang meningkatkan dan memperkuatkan prinsip-prinsip tersebut. Sehingga dapat dikatakan bahwa penerapan budaya organisasi sangat diperlukan bagi setiap organisasi sebab dengan budaya akan mempermudah timbulnya komitmen pada seseorang yang lebih luas daripada kepercayaan diri individual seseorang.

Pentingnya fungsi dan peran budaya organisasi dalam Lingkup Kopertis Wilayah IX pada PTS di Makassar, maka dari hasil pengamatan di lapangan melalui penyebaran kuesioner pada sejumlah dosen Kopertis Wilayah IX yang diperbantukan pada PTS di Makassar menunjukkan budaya organisasi yang dilakukan selama ini dapat meningkatkan kepuasan dosen namun tidak berpengaruh signifikan. Hal ini diseabkan karena hasil persepsi dosen mengenai budaya organisasi dimana Kopertis masih kurang memberikan kesempatan kepada setiap dosen dalam memberikan inovasi dalam pelaksanaan tugas pekerjaan dan selain itu Kopertis kurang mendukung setiap dosen untuk bekerja dalam tim untuk pelaksanaan tugas pekerjaan.

Masalah motivasi kerja merupakan bagian yang terpenting dalam meningkatkan kepuasan kerja dosen. Artinya secara empirik dinyatakan bahwa makin tinggi motivasi yang dimiliki maka akan berdampak terhadap kepuasan kerja dosen Kopertis Wilayah IX yang diperbantukan pada PTS di Makassar. 


\section{DAFTAR PUSTAKA}

Blazey, Mark. L, Davison Karen. S dan Evans, John. P.; 2003, "Insights to Performance Excellence in Education 2003", American Society for Quality, Milwaukee, Wisconsin,

Mulyadi, Deddy, 2015, Perilaku Organisasi dan Kepemimpinan Pelayanan : Konsep dan Aplikasi Administrasi, Manajemen dan Organisasi Modern, penerbit : Alfabeta, Bandung.

Mulyasa, E. 2012. Kurikulum Berbasis Kompetensi. Konsep, Karakteristik, dan Implementasi. Bandung : PT Remaja Rosdakarya.

Robbins, Stephen, P. dan Coulter Mary, 2012, Management, New Jersey, Pearson Education, Inc.

Smith, S.C. et.al. 2002, School Leadership Handbook for Survival. Oregon: Cldearing House on Educational Management

Sri Trisnaningsih, 2011, Faktor-faktor yang mempengaruhi kinerja dosen akuntansi. Jurnal Akuntansi \& Auditing Volume 8/No. 1/November 2011: 1-94

Sudjana, Nana. 2002. Penelitian dan Penilaian Pendidikan. Penerbit : Sinar Baru, Bandung

Sunyoto, Danang, 2012, Manajemen Sumber Daya Manusia, cetakan pertama, Yogyakarta : penerbit : CAPS.

Suparlan. 2006, Guru Sebagai Profesi. Penerbit : Hikayat Publishing, Yogyakarta

Widodo, Suparno Eko, 2015, Manajemen Pengembangan Sumber Daya Manusia, cetakan pertama, penerbit : Pustaka Pelajar, Yogyakarta.

Zamroni, 2011, Paradigma Pendidikan Masa Depan, Penerbit : Bigraf Publishing, Yogyakarta. 